Yayınlayan: Ankara Üniversitesi KASAUM

Adres: Kadın Sorunları Araştırma ve Uygulama Merkezi, Cebeci 06590 Ankara

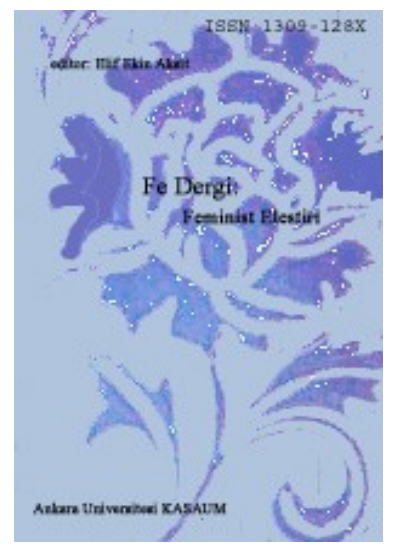

Fe Dergi: Feminist Eleştiri Cilt 5 Sayı 1

Erişim bilgileri, makale sunumu ve ayrıntılar için:

http://cins.ankara.edu.tr/

Suriyeli yazar Dima Vannus'tan “Seher” adlı öykü

Bülent Korkmaz

Çevrimiçi yayına başlama tarihi: 15 Haziran 2013

Bu makaleyi alıntılamak için: Bülent Korkmaz, "Suriyeli yazar Dima Vannus’tan "Seher" adlı öykü," Fe Dergi 5, no. 1 (2013), 12-14.

URL: http://cins.ankara.edu.tr/9_2.html

$\mathrm{Bu}$ eser akademik faaliyetlerde ve referans verilerek kullanılabilir. Hiçbir şekilde izin alınmaksızın çoğaltılamaz. 


\title{
Suriyeli yazar Dima Vannus’tan “Seher” adlı öykü
}

\section{Bülent Korkmaz*}

\author{
Suriye'li genç kuşak kadın yazarlardan Dima Vannus'un "Seher” adlı öyküsü bu çalışmaya konu \\ olarak seçilmiştir. \\ Yazarın kısa yaşam öyküsü ile başlayacak olan çalışma, öykünün değerlendirmesini içerecek ve Türkçe \\ çevirisi ile tamamlanacaktır. \\ Anahtar Sözcükler: Dima Vannus, Orta Doğu, kısa öykü, gündelik hayat, Doğu
}

\begin{abstract}
"Sahar" by the Syrian writer Dima Wannous
A short story of Syrian young women writers Dima Wannous "Sahar" was chosen as the subject of this study.

The study will begin with the story of the author's life, including her assessment of the short story, and will be completed with Turkish translation.

Key words: Dima Wannous, Middle East, short story, daily life, Eastern
\end{abstract}

\section{Giriş}

Şam ve Sorbonne üniversitelerinde Fransız edebiyatı okuyan Dima Vannus, Fransa, Leon üniversitesinden çevirmenlik diploması aldı ve 2003-2006 yılları arasında Şam radyosu Fransızca haberler bölümünde çevirmen olarak çalıştı. Ayrıca, 2003 yılından bu yana, Es-Sefir, El-Ahbar ve El-Hayat gazetelerinde politik ve kültürel içerikli yazılar yazmakta.

Tefasil (Ayrıntılar) adlı öykü kitabı, 2007 yılında Daru’l-Meda yayınevi tarafından yayımlandı.

\section{Öyküye Dair}

Suriye'de gündelik hayatın ironik bir anlatısı olarak niteleyeceğimiz öykü, sıradan bir ev kadının yaşam biçimini gözler önüne sermeye çalışır. Öyküde yer alan kahramanların ve yaşam biçimlerinin olumsuz bir bakışla resmedilmesi aracılığıyla yazar, kendi toplumundaki baskın kadın algısını mizahi bir dille eleştirir. Anlatıcı dilin ikinci el oryantalist bir dil olduğu, klişe doğulu kadın imajının batılı yaşam biçimi ve kadın algısı dile getirilmeksizin, çağrışımlar aracılığıyla yine bir doğulu kadın yazar tarafından işlevselleştirilmesiyle açığa çıkar. Gündelik yaşamın kısıtlı olanaklarını zenginleştirme çabalarının yol açtığı süregiden bir kısır döngü anlatısı "Her Perşembe adet olduğu üzere" cümlesiyle vurgulanarak geleneğe gönderme yapılır.

Öykünün kahramanı Seher'in tıpkı alanına hâkim bir uzman bilim insanının nitelenebileceği ölçüde evinin tüm ayrıntılarına vakıf ve meraklı bir araştırmacı titizliğiyle yaptığı gözlemler, okuyucuya ironik bir dille anlatılırken küçük burjuvalığı ise "hayatındaki ayrıntıları biriktirme tutkusu" cümlesi ile vurgulanır. Araştırmacı kişiliğine ait "damarlarında dolaşan bu kaygı" onun "tüm enerjisini gözetlemeye ve incelemeye" yönlendirir. Bu çaba neredeyse araştırma nesnesi ile hemhal olacak denli bir ilginin ifadesi ile devam eder.

Gözlem ve inceleme safhası bir sonraki aşamada yerini karşılaştırma uğraşına bırakır. Seher'in kocası Mahmut, bir yandan ihtiyar komşunun yaşlılığına karşılık gençliği ile kıyaslanırken öte yandan uyumsuz ve yetersiz bedensel özellikleri aracılığıyla onun tam zıttı özelliklere sahip Seher'le kıyaslanır. Kıyaslamaların sonucunda ortaya çıkan farklılık, alaycı bir gülümsemeyle örtük üstünlük duygusunun verdiği dinsel bir çekinceyi içerir.

Öykünün bir başka kadın figürü Sümeyye ise benzer bir yaşam biçimin sonucunda biriktirmiş olduğu gözlem ve deneyimlere ait hikâyelerini, bedenini saran mantosunun kıvrımlarına içkin bir halde, bir an önce paylaşılmaya hazır bir arzuyu anlatan bir sürat duygusu aracılığıyla sahneye girer. Yaşanacak olanların adetleşmiş sürekliliği, onları ne yapacaklarını konuşmaksızın bilen birer kişiliğe dönüştürmüştür.

\footnotetext{
* Öğretim Görevlisi,Yıldırım Bayezit Üniversitesi Arap Dili ve Edebiyatı.
} 
Yapılmış olan tüm gözlem, inceleme ve karşılaştırmaların sonuçları alanın otoritesiymişçesine ortaya çıkan Hacı Meryem aracılığıyla anlamlandırılacaktır. Hac ibadetini yapmış dindar bir dul olan Hacı Meryem, görünüşte sahip olduğu dinsel kisve aracılığıyla araştırmacı kişiliklerin eğitici ve değerlendirici teorik bilgilerini "Kuran'dan ayetler okumak ... fikıl ve tefsir dersleri” ile tamamlarken öte yandan "dindarca" görünüşünü tamamlayan "peçeyi çıkardığında” Seher ve Sümeyye’nin biriktirmiş oldukları öykülerin kimseyle paylaşamadıkları ve iç yapısına vakıf olamadıkları “çelişkilere dair” açıklamalarla sürdürür. Hacı Meryem’in din dışı yaşama dair otoritesi ise hakkında yayılan ancak Seher'in hep reddettiği dedikodular aracılığıyla sağlanır. Seher ve Sümeyye'ye kıyasla daha hareketli bir sosyal yaşam ve çeşitli ilişkilere sahip kişiliği aracılığıyla Hacı Meryem, sadece dini bilgiler hakkında değil "güzel duygular" hakkında da eğitici bir kişiliğe sahiptir. Kadın-erkek ilişkisine sigara alışkanlığına dair Mahmut’un onu "iğrenç duman kokusu” ile nitelemesinin onaylanması ve onu "bir erkek alışkanlığı” olarak görmesinin sorgulamasız kabulünün yanı sıra Hacı Meryem'in "kişi başı üç yüz lira” ücret mukabili verdiği dersleri onaylamaya mecbur bırakılması dışında değinilmez.

Haftalık bir ritüel olarak cinselliğin kurgulanmasına uzun vakitler harcanan bir makyaj ve süslenmeyi takiben "oryantal” bir müzik eşliğinde geçilir. Gerçekçi olmayan bir kanıksanmışlık görüntüsü içindeki Mahmut'un heyecanı üst üste içtiği sigaralar ve "şehvetli ağzıyla" çiğnediği "domates ve salatalık dilimleri" aracılığıyla yalanlanırken, Seher'in bir yandan ter içinde kalıncaya dek dans ederken diğer yandan da çıkardığı "tuhaf ve erotik bir takım sözcükler" aracılığıyla zirveye ulaşan heyecan duygusu, Seher'in kapalı gözlerinin açılması ile son bulur. Hacı Meryem'in vermiş olduğu derslerdeki sorulardan birinin cevabı ise aktivitenin meşruiyetini sağlar.

\section{Seher}

Seher, her Perşembe sabahı âdet olduğu üzere, odasının penceresini açar ve komşularının pencerelerinden beslenmeye başlar. Hayal gücü, deneyimlemediği hayatların sırlarına vakıf olmak için perdelerin ötesine sızar. Hayali görüntülerin baştan çıkarıcı çekiciliği ile zaten onlarla dolu olan hafızasına yeni bir öykü daha ekler. Penceresinin manzarası, evde gerçekten Seher'e ait olan tek köşe olabilir. Evin, üzerindeki etkisi büyüktür, hatta kocası Mahmut'tan da fazla. Duvarlarına ve ince ayrıntılarına varıncaya dek her noktasını bilir. Döşeme bile, bazı kısımlarından aşınmış parlak bir mermer sayfaymışçasına, hafızasına kazınmıştır. Seher, yeşil gözlerini kapasa bile beyaz mermer üzerindeki eğri büğrü kahverengi çizikleri bulabilir, hatta eksiksiz tüm ayrıntılarıyla pencerenin yakın köşesinde yer alan ve her akşam Mahmut'un dinlenmek için üzerine uzandığı, yılların etkisiyle rengi solmuş eski moda küçük kanepeyi betimleyebilirdi.

Hayatındaki ayrıntıları biriktirme tutkusu, onun ruhunda herhangi bir milli yahut entelektüel kaygıdan farksız bir önem kazandı. Damarlarında dolaşan bu kaygı, onu her Perşembe sabahı harekete geçirir. Narin bedeni, onu tüm ciddiyeti içinde pencereye doğru sürükler, onu açar, öğlene kadar tüm enerjisini gözetlemeye ve incelemeye ayırır. Tüm duyularını bilmediği dünyalara girmeye, en küçük ayrıntılarına varıncaya dek yudumlamaya hasreder. Penceresine dolan şeffaf bir bulut gibi yemek kokusu kokar. Diğer kadınların pencerelerini açmasıyla kovulan uyku kokusunu solur. Uzun bir uykunun mahmurluğunu taşıyan bedenlerin kokusunu içine çeker. Her sabah süt satmak için geçen ya da milli kutlamalarda satmak üzere bayrakları, posterleri, afişleri ve flamaları saklayan komşularına bakışları takılır. Sabahleyin, kahvesini karısıyla içerken, ona gizlice bakar. Gür saçları, kızılboyanın izlerini taşımasına karşın ağarmış ve yastığın etkisiyle düzleşmiştir. Yüzündeki al yanakları, kırışık ve göbeği de her geçen gün büyümektedir.

Seher, çaktırmadan güler sonra, Allah'ın Mahmut'u sadece birkaç yıl içinde yağla dolu bir göbeğe dönüştürerek onu cezalandırmasından korkar. Vücudunu gözünün önüne getirir ve acaba nasıl görünecek diye ona bir göbek uydurur; tabii ki de kesinlikle uygun olmaz. Mahmut, sadece kısa değil, üstelik bedeni de çelimsizdir ve çıplak olmasına rağmen sanki yün bir kazak giymişçesine kaba siyah kıllarla kaplıdır. O, Seherin kendisinden daha çekici olduğunu çok iyi bilir. Vücudu yumuşak ve son derece uyumludur. Uzun boyu ve narin yapısı nefes kesicidir. Ağzı, Mahmut'un annesinin tanımıyla, kiraz tanesi gibidir. Tatlı, açık yeşil renkli ve yağmur damlası gibi badem gözlüdür. Cildi beyaz, sıkı ve pürüzsüzdür; herhangi bir leke yahut sarkma ile zarar görmemiştir.

Bir keresinde Komşusu Sümeyye'nin bedenine değdiği gibi, bir gün nazar değmemiştir Seher'e. Gözlerini fal taşı gibi açarak bakmalarına rağmen, ancak sol ya da sağ yarısını kuşatabilir gözbebekleri; tüm bedenini değil.

Her Perşembe âdet olduğu üzere, tam gün ortasında, esmer vücudunu sararak gizleyen ve kıvrımlarında hikâyeler saklı uzun, siyah mantosuyla Sümeyye ilerlemektedir. Uzun ve yorucu merdivenleri çıkar. Kapının 
zilini çalar. Fırtına gibi pervasızca Seher'in evine girer. Sümeyye, daha zili çalarken siyah mantosunun düğmelerini çözmeye başlar ve çoğunlukla da Seher kapıyı açmadan son düğmeye ulaşır. Vücudunu azat edercesine ve sanki kara bir duman ve toz bulutu taşıyan firtına şeklinde uçuşan ipek mantosunun eteklerini savurarak içeri dalar. Seher, sabah anılarını ezberlemek için tekrar pencerenin altına oturur. Sanki hayallerine eklenecek yeni sahnelerin kurgulanmasını istercesine sessizdir. Sümeyye de, Seherle aralarında ilan edilmemiş bir gizli anlaşma varmış gibi onun sakin ve dikkatlice düşüncelerini düzenlemesine imkân vermek için susar. Her Perşembe âdet olduğu üzere, Hacı Meryem, Kuran'dan ayetler okumak ve her ikisini de fikıh ve tefsir derslerinde boğmak üzere gelir. Hacca gitmiş olduğu için Hac, örtünme ve dini bilgileri güçlüdür. Meryem, hacca gitmiş olduğu için dindarca bir peçe takar. Ancak peçeyi çıkardığında sözleri, dinden ve etkileyici hac deneyimlerinden uzak, tamamen farklı bir izlenim sergiler. Bu durum, Seher ve Sümeyye’yi dini konuları değil de güzel duygular hakkında onu dinlemek istemeye heveslendirir. Gür ve parlak saçlarıyla onları etkiler, narin ve yumuşak ellerinin bir tek hareketiyle hayal dünyalarına gizlice sokulur. Dengeli ve güven verici sözleriyle onları duygusal yönden doyurur. Kişi başı üç yüz lira karşılığında. Başlangıçta Mahmut, istenen ücreti ödemeyi reddetti; ne var ki Seher, onu yumuşayıncaya kadar mahşer azabıyla tehdit etti.

Meryem, ölen kocasının ardından tekrar evlenmemiş bir duldur. Din dersleri, onun yalnızlığını sona erdirdi. Mütevazı bir yaşam ile ihtiyaç duyduğu azı̆̆ı elde etmesini sağladı. Komşular, Meryem'in ikinci kez evlenmeyi reddetmesine dair hikâyeler anlatmaktan bir gün olsun geri durmadılar. Bunlardan biri, çarşıda duyulur korkusuyla onunla evlilikten vazgeçmiş “Hamidiye” çarşısından zengin bir tüccar ile Meryem'in gizli ilişkisini anlatır. Zira kayınpederi, doğunun en büyük antika sağlayıcı tüccarlarından biriydi. Bir diğeri ise, Meryem'in "Bludan" bölgesinde bir subayın eşliğinde görülmesi hakkında anlatılan bir hikâyedir. Seher, komşuların anlattıklarını hep reddetti ve hayal dünyasındaki kusursuz Meryem imajına toz kondurmamayı sürdürdü.

Âdet olduğu üzere, Hacı, deri çantasından, kardeşinin hapisteyken onun için boncuktan yapmış olduğu üç tespih çıkardı. Tespihlerle "Subhanallah" çekmeye başladılar. Meryem, ezberden Kuran ayetlerini okudu, Seher ve Sümeyye de ardından tekrar ettiler, "Sadak'Allahu'l-Azim”. Küçük mutfakta su kaynıyor ve islık çalıyor. Seher kahve pişirirken, Sümeyye de, Mahmut'un Humus’tan dönüş yolunda aldığı peynir tatlısından üç tabak hazırlıyor. Seher, dersin ikinci kısmını sever. Kahve içilir ve Seher büyük bir günah işleyerek Meryem'den bir sigara aşırır, ardından, tıpkı Mahmut'un nitelemiş olduğu gibi, iğrenç duman kokusunu yok etmek için lavaboya koşar. Aslında Mahmut'ta sigara içer ancak Seher'in içmesinden hoşlanmaz ve onu bir erkek alışkanlığı olarak görür. Bunların ardından Seher, Hacı' ya yakın oturur ve utandıran sorularını yağdırmaya başlar. Haram ve helal; Cennet ve cehennem; İyilik ve kötülük ile üzerindeki etkisinin çok büyük, hatta kocası Mahmut'tan da büyük olduğu bu evde Seher'in gerçekten sahip olduğu bu biricik köşesi, penceresinde, gördüğü tüm çelişkilere dair.

Her Perşembe akşamı adet olunduğu üzere, Seher, aynanın önünde uzun vakit harcar. Yeşil gözlerine sürme çeker ki yeşil renk kaybolur bir baştan çıkartıcı denizde. Sarı saçları, fildişi bir tarakla istila olur. Yanakları, parlak kırmızıyla renklenir. Kalın dudakları, kırmızıya çalan bir kahve tonuyla parıldar. Sabah dersinden, haram ve helalden, kendini soyutlar ve ciddileşir. Yakut kırmızısı, çınlayan süslerle donanmış ve Seher'in kadınsı hatlarını ön plana çıkarmak için bazı mavi işlemelerle bezenmiş dansöz kıyafetini giyer. Son olarak kıyafet, neredeyse dokuz santimetrelik topuklu şeffaf pabuç ile tamamlanır ki bu, gerçekleşebilecek ihtimalleri çoğaltır.

Her Perşembe akşamı adet olduğu üzere, Mahmut, özlemle dolu bir halde bedenini evlilik yatağına uzatıverir. Sabırla maskelenmiş bir heyecan içinde sigara üstüne sigara içer. Perşembe buluşmasının beklentisiyle dolu, şehvetli ağzıyla domates ve salatalık dilimlerini çiğner.

Her Perşembe adet olduğu üzere, teybe bir oryantal müzik kaseti takar. Seher, koreografik hareketlerle çılgınca salınır. Terden ıslanmış göğüslerini sallar. Tuhaf ve erotik bir takım sözcükler çıkararak gözlerini kapar. O, sadece kocasının sabrı tükenip de partinin sonuna gelmiş olduklarında gözlerini açar.

"Kahpelik haram mi? Hac1?"

"Evlilik içinde değil."

Dima Wannous

تقاصيل -( مجموعة قصصية ) دار المك 2007, ديمة ونوس

Wannous, Dima, "Tefasil”, Dar al-Mada, Damascus, 2007.

http://www.banipal.co.uk/selections/60/176/dima-wannous/ 